\title{
Platelet Distribution Width
}

National Cancer Institute

\section{Source}

National Cancer Institute. Platelet Distribution Width. NCI Thesaurus. Code C81962.

A measurement of the range of platelet sizes in a blood specimen. 